\title{
LOS USOS DEL RÍO COLORADO Y LA SUBSISTENCIA DE LOS INDÍGENAS CUCAPÁ EN EL VALLE DE MEXICALI. 1852-1944
}

\author{
Por \\ José Alfredo Gómez Estrada*
}

\begin{abstract}
RESUMEN
Este artículo describe ómo en las tres primeras décadas del presente siglo la población estadunidense y mexicana establecidas en el Valle Imperial y valle de Mexicali utilizaron el río Colorado para desarrollar una moderna agricultura de irrigación en su zona deltaica. Establece conexiones entre eventos y procesos relacionados con el desarrollo agrícola en los valles mencionados e importantes cambios en la forma de subsistencia de los indígenas cucapá, antiguos habitantes de esta región.
\end{abstract}

\begin{abstract}
This article describes how, in the first three decades of the present century, the population of the United States and Mexico living in the Imperial Valley and the Mexicali Valley used the Colorado River to develop a modern, irrigation-based agriculture in the river's delta zone. It established connections between events and processes related to the Cucapá Indians, the native inhabitants of this region.
\end{abstract}

\section{INTRODUCCIÓN}

La creación de un nuevo límite fronterizo entre México y Estados Unidos, después de 1848, tuvo entre otros resultados que el río Colorado y el extenso valle formado por éste en la región cercana a su desembocadura, quedaran divididos. El valle, en el que actualmente se localizan las zonas fronterizas de los estados de Baja California, Sonora, California y Arizona, estaba habitado en su parte sureña por aborigenes llamados cucapá, quienes al establecerse la nueva frontera se hallaban organizados en una sociedad de tecnología simple.

* Investigador del Instituto de Investigaciones Históricas de la Universidad Autónoma de Baja California 
Actualmente existen algunos estudios que, de manera más o menos completa, describen cómo eran los aspectos materiales y simbolicos de las sociedades indigenas en el norte de Baja California. En el caso de los cucapá, dichos aspectos son descritos ampliamente en el estudio etnografico titulado Cocopa Ethnography, realizado por William $\mathrm{H}$. Kelly en la década de 1940. Este trabajo, salvo por algunos datos históricos aislados, presenta de manera estática a la cultura de los cucapá, delimitándola temporalmente entre las últimas décadas del siglo XIX y las primeras del xX. Una revision somera de fuentes bibliograficas indican que justamente en ese periodo estaba gestándose en la región un nuevo orden social y cultural que tendría repercusiones en las sociedades aborigenes que la habitaban, es por ello que resulta interesante indagar la dinámica acaecida en ese tiempo. Hoy día se conoce poco la historia de los grupos indigenas de Baja California pues, dada su condición ágrafa, ninguno dejo testimonios escritos. Por otra parte, la version occidental se debe a notas de misioneros, exploradores, viajeros y gambusinos que entraron en contacto con ellos, anotaciones breves que por lo general se refieren a sus costumbres y a sus formas de subsistencia. Asf pues, la reconstrucción historica, de por sf limitada, se restringe más en el caso de las comunidades indigenas. Ante la carencia de fuentes especificas, queda sólo la posibilidad de establecer aspectos generales de su devenir historico, a partir de la información relativa a los eventos y procesos regionales que tuvieron influencia en la vida de estas comunidades. Este trabajo, por ejemplo, tiene como objetivo contextualizar aquellos que incidieron en la sociedad y en la cultura de los cucapá. A saber: la navegación comercial en el río Colorado a partir del año 1852, el descubrimiento del potencial agrícola de la zona deltaica en las últimas décadas del siglo XIX; la colonización del Valle Imperial, iniciada en 1900; la desviación de la corriente del río acaecida en 1905; el desarrollo agrícola del valle de Mexicali y la construcción de grandes presas para controlar y almacenar el agua del Colorado en la década de los años treinta.

Los cucapá vivieron en las inmediaciones del bajo Colorado, en un territorio que era potencialmente rico para la agricultura por la disponibilidad de agua y de fértiles tierras abonadas por la corriente fangosa del río. La dependencia de los cucapá respecto al medio y la condición fronteriza de la zona que habitaban, determinaron que historicamente fueran influenciados por eventos y procesos relacionados con el establecimiento en el valle de una población blanca, portadora de tecnologías mucho más avanzadas que la utilizada por los indígenas en la explotación del medio.

Hace cientos de años la región deltaica del río Colorado estuvo habitada únicamente por grupos aborigenes seminómadas, entre ellos estaban los 
Ulamados quechanos, ${ }^{1}$ los halchidoma, los kuamai(?) y los cucapá. Estos últimos vivieron diseminados en parte de lo que hoy día se conoce como valle de Mexicali. La antigüedad de los asentamientos cucapá en el bajo delta es desconocida, los arqueólogos ban encontrado restos de cerámica que datan del año 800 de nuestra era pero no hay evidencias que permitan atribuirles esos vestigios (Frederic, 1974), sólo se sabe, con base en las crónicas de los exploradores españoles, que estos indígenas vivieron en el area desde el siglo Xvi. ${ }^{2}$

La subsistencia de los cucapá, al igual que la de las otras tribus de la región, dependió de los comestibles que encontraron en el medio durante las estaciones del año y de su habilidad para apropiárselos mediante la caza, la pesca y la recolección. Al margen de estas actividades desarrollaron otra un poco más compleja: la agricultura, y aunque para llevar a cabo esta actividad requirieron del agua del río Colorado, no lograron ejercer sobre la corriente ningún control, ${ }^{3}$ más bien aprovecharon la humedad derivada de sus desbordamientos cíclicos. Por esta razón, realizaron sólo las siembras que el curso del río les permitía, sus cosechas fueron reducidas y los productos agrícolas no fueron otra cosa que un complemento en su dieta (Kelly, 1977:29; Castetter y Bell, 1951:238).

A pesar de la presencia temprana de grupos humanos en la region, por siglos imperó en el valle un orden casi natural. En el transcurso de un largo periodo, los cucapá, organizados en bandas, acumularon conocimiento sobre el medio para adaptarse a él, sin capacidad para transformarlo, pues sus herramientas fueron tan sencillas que apenas se diferenciaron de los elementos presentes en el paisaje. Con excepción de las piezas de cerámica y de cestería, cuya fabricación requería dedicación y el manejo de una técnica depurada, los instrumentos producidos por los cucapá para extraer, procesar, transportar y almacenar alimentos era de madera y piedra ligeramente trabajadas. Su instrumental no eran en ningún modo copioso: en la agricultura utilizaban sólo dos palos, con uno puntiagudo perforaban el suelo y con el otro, que era plano en un extremo, cortaban la

\footnotetext{
1 Algunos autores identifican a este grupo como yumas. Los indígenas se llaman entre ellos mismos quechans.

2 Hernando de Alarcón, explorador español, registró en el año 1540 la existencia de diez grupos que vivían en el delta del río, al margen de sus riberas, se supone que uno de éstos eran cucapás. (Véase Forbes, 1965). En 1604, durante una expedición realizada en la región por Juan de Oñate se identificó a un grupo con el nombre de cocopa. (Véase Alvarez de Williams, 1975:33).

3 Por medio de represos, bordos y zanjas los indígenas intentaron controlar la corriente variable del río Colorado. Es obvio que con las herramientas que tenían a disposición no pudieron construir un eficiente sistema de irrigación. (Véase Kelly William, 1977;27).
} 
hierba extendida en los terrenos. Para pescar tenían dos tipos de redes, una compuesta de varas cruzadas y otra rectangular de cordel tejido que ataban a estacas dentro del agua. Cazaban con el recurso del arco y la flecha, aunque también utilizaban trampas para atrapar mamiferos pequeños. En las faenas de recolección sus instrumentos eran simples palos con los que cortaban o desenterraban las plantas, y para transportar hierbas, granos o semillas, se valían de cestos o redes de fibra vegetal tejida. El único medio de transporte conocido por ellos eran las balsas que hacian con tule, junco y troncos de árbol (Kelly, 1977:52-53).

A la llegada de los españoles, acaecida en Baja California en la tercera década del siglo XVI, los diversos grupos nativos, incluidos los cucapá, se hallaban organizados en sociedades tribales. Del año 1697 al 1849 , el modo de vida aborigen fue drásticamente alterado en razón de importantes cambios introducidos por los misioneros, quienes para realizar la evangelización utilizaron el recurso de las misiones que establecieron en los territorios indigenas. La colonización misional, que implico el contacto entre los occidentales y los grupos nativos supuso, además de la catequización, una transformación drástica de todas las culturas aborígenes, pero los cucapá estuvieron al margen de este proceso de aculturación inducido. La región del bajo delta del río Colorado permaneció prácticamente fuera del alcance de los españoles, por esta razón, los cucapá no conocieron ninguna misión en su territorio, de hecho, sus encuentros con los hispanos fueron esporadicos ${ }^{4}$ y en consecuencia, poco significativos en términos de cambios culturales por contacto. No fue sino hasta la segunda mitad del siglo XIX cuando éstos comenzaron a darse, como resultado de las relaciones sostenidas con grupos de estadunidenses, y en menor proporción con mexicanos, a raíz de que unos utilizaron el río Colorado como vía de transporte y los otros se establecieron en la región deltaica, con el propósito de aprovechar sus recursos naturales. Los elementos adaptados entonces por los cucapá no representaron alteraciones drásticas en su forma de vida y debido a que el medio ambiente, particularmente el rfo Colorado, no fue modificado por la población blanca, los indígenas conservaron su territorio y autonomía. Sin embargo, el establecimiento permanente de una población blanca y mestiza, cuyo número creció a partir del año 1900 , y

\footnotetext{
4 En el mes de enero de 1781 un grupo numeroso de españoles se estableció en el área de confluencia de los ríos Gila y Colorado y comenzaron a edificar los pueblos Concepción y San Pedro y San Pablo en el territorio de los quechanos, localizado al norte del habitado por los cucapá En julio de ese mismo af́o, los quechanos atacaron a los pueblos fundados, causaron importantes bajas entre los hispanos y los obligaron a retirarse. Como resultado de ese levantamiento indígena fueron suspendidos los planes de ocupación de la región del bajo rio Colorado (Forbes, 1965: 191 y 204).
} 
la explotación de los recursos naturales por parte de ésta, provocaron posteriormente, en sólo cuatro décadas, una serie de cambios irreversibles que influyeron negativamente en la reproducción de la sociedad y la cultura de los cucapá.

\section{LA NAVEGACIÓN COMERCIAL EN EL RÍO COLORADO 1852-1877}

Después de la guerra con Estados Unidos, México firmó en febrero de 1848 el Tratado de Guadalupe Hidalgo, mediante el cual cedió a su adversario los territorios de los actuales estados de California, Nuevo México, Arizona, Nevada, Colorado y Utah. Al moverse la frontera hacia el sur, el rio Colorado, que recorre parciaimente esos estados, quedo casi en su totalidad dentro de la unión americana. ${ }^{5}$ Una semana después de que el tratado fuese suscrito, unos mineros descubrieron oro en las cercantas de Sacramento, California y el evento provoc6 una corriente migratoria hacia ese punto como no se habfa presentado antes en el mundo (Huberman, 1977:158). Para trasladarse de las ciudades y poblados del este de la union americana a los campos aurfferos de California, los aspirantes al oro viajaron por todas las rutas posibles. Una de ellas fue la del suroeste, que en un trecho corra paralela al río Gila y cruzaba la confluencia de éste con el Colorado (Crowe y Brinckerhoff, 1976:1-2), internándose en el territorio de los quechanos y tangencialmente en el de los cucapá. Como resultado de esa migración masiva a California, el ejército de los Estados Unidos se vio obligado a establecer una guarnición militar en la confluencia de los ríos. Dicha guarnición, llamada Fuerte Independencia, (posteriormente Fuerte Yuma) tuvo como fin proteger a los inmigrantes, que en breve comenzaron a ser hostigados por los quechanos (Kroeber, 1980:190). Desde el principio quedó claro que mantener a la tropa del Fuerte Independencia serfa más diff́cil que controlar a los indigenas hostiles. El aislamiento de la region, enclavada en un extenso e incomunicado desierto, hizo necesaria la búsqueda de una vía de fácil acceso para abastecer a los soldados (Leavitt, 1943:2-3). Poco después de establecer dicha vía, que fue maritima alrededor de la penf́nsula de Baja California y fluvial dentro del río Colorado, comenzo un periodo de intercambio comercial a través del rio. El traslado de alimentos y productos manufacturados, que al principio se dedico únicamente para abastecer a la tropa del fuerte, se amplio diezaños después

5 A México le quedaron sólo 125 kilómetros del río Colorado que empiezan en un punto cercano a la confluencia de éste con el Gila y terminan ea la desembocadura, en el golfo de California. 
a los mineros de los poblados de Arizona. Así, entre los años 1862 y 1877 hubo un importante flujo de mercancías y minerales que fueron transportados en barcos de vapor por una empresa naviera llamada Colorado Steam Navigation Company. Los barcos de vapor de esta compañía utilizaron como combustible la madera que provenía de los mezquitales y las alamedas crecidas en las riberas del río. Para suministrarla a los vapores, la empresa fijó algunos sitios de abastecimiento, allí enseño a los indios de la región a talar árboles y a preparar fardos de la leña requerida por las embarcaciones. Por cada atado les pagaba dos dolares con cincuenta centavos (Leavitt, 1943:161). Los cucapá no sólo se ocuparon en la extracción de madera, también se dedicaron al corte de zacate para vender, y algunos de ellos, conocedores del comportamiento del río, fueron empleados por la compañía transportista como parte de la cuadrilla de los barcos (Blanco, 1978:133; Kniffen, 1933:57). En el año 1874, cuando el comercio a través del río estaba en pleno apogeo, una empresa colonizadora, la Compañía Mexicana Agrícola Industrial y Colonizadora de Terrenos del Colorado, estableció en territorio cucapá un núcleo de población llamado Colonia Lerdo. Inicialmente, los habitantes de la colonia se dedicaron a la extracción de un cáñamo silvestre que crecía abundantemente en los terrenos del río, pero después realizaron algunos cultivos de trigo, cebada, alfalfa y algodon. Aunque la Colonia Lerdo logro cierto progreso y llegó a tener 800 habitantes, entre los cuales se encontraban 148 cucapás, empleados por la compañía en el corte de cáñamo, ${ }^{6}$ las actividades decayeron súbitamente en 1877 , a causa de una severa inundación (Herrera, 1976:69; Hendricks, 1976). En el transcurso de los veinticinco años que duró el trafico comercial y los tres que operó la compañía colonizadora, los cucapá sostuvieron un trato constante con estadunidenses y mexicanos. El resultado de este contacto fue que los indigenas empezaron a utilizar herramientas tales como cuchillos, marros y azadones (Kelly, 1977:53). Por otra parte, se aficionaron a las prendas de vestir del hombre blanco y adquirieron gusto por alimentos como el azúcar y la harina. Gradualmente se iniciaron también en el consumo del tabaco y del cafe (Kniffen, 1933:56), pero sin duda lo más importante fue que aprendieron a usar el dinero y comenzaron a combinar sus tareas tradicionales de subsistencia con el trabajo remunerado?

6 Informe que rinde la dirección de la Companía Mexicana Agrícola Industrial y Colonizadora de Terrenos del Colorado, presentada en San Francisco de California a sus consocios y comitentes. En junta de 7 de octubre de 1874. San Francisco. Cosmopolitan Steam Printing Company, 1874. 


\section{EL DESARROLLO AGRÍCOLA EN EL VALLE IMPERIAL; LA FUGA DEL RÍO COLORADO Y LA DISPERSIÓN DE LA TRIBU CUCAPÁ 1900-1909}

En las últimas décadas del siglo XIX algunos empresarios estadunidenses realizaron proyectos para derivar el agua del río Colorado y desarrollar el potencial agrícola de la región del delta, pero no fue sino hasta el año 1900 cuando dichos proyectos pudieron concretizarse, gracias a las acciones emprendidas por el ingeniero Charles Robinson Rockwood y un grupo de capitalistas interesados en el desarrollo agrícola y en la colonización del área. En ese tiempo, el valle, dividido por una línea todavía imaginaria, ofrecía más posibilidades en la sección mexicana, donde se había establecido la colonia Lerdo, no obstante, la colonización habría de comenzar en el lado norte de la frontera. En el año 1895 el ingeniero Rockwood elaboró un plan de irrigación que contempló la conducción del Colorado con el proposito de irrigar una parte de los terrenos del valle, localizados en el lado estadunidense. Planeó derivar el agua en un sitio conocido como Pilot Knob, cercano a la línea internacional, donde comenzaría la construcción de un canal dirigido hacia el sur. Luego de entrar en territorio mexicano, dicho canal se conectaría con el río Álamo, lecho abandonado del Colorado, que llevaría el agua hacia el oeste, a lo largo de cuarenta millas. La corriente continuaría después por un canal construido que finalmente se internaría en California (Henderson, 1968:127). El recorrido del agua dentro de México era inevitable, puesto que se hacía necesario evadir una zona de médanos existentes entre el río y el territorio

7 Una de las principales características de las sociedades de tecnología simple es la posesión de un equipo productivo relativamente sencillo. Sin energía animal o hidráulica para elevación o tracción, la capacidad productiva de estas sociedades se reduce a la fuerza humana, restringida por el uso de utensilios manuales como el arco y la red de pesca. Otras características son la carencia de medios de transporte y las dificultades de almacenamiento. Dada la dificultad para producir bienes duraderos, para almacenar y acumular alimentos, los individuos subsisten con los que obtienen cotidianamente durante las estaciones del año, su esfuerzo productivo es capaz de anticipar las necesidades futuras sólo por periodos cortos y están propensos a padecer escasez de alimentos. Al establecer contacto con grupos portadores de la cultura occidental, las sociedades de tecnología simple tienen acceso a valores y bienes producidos mediante tecnologías que están muy lejos de su capacidad. La circulación de moneda, con valor en una cercana economía de mercado, crea la posibilidad de que los individuos que las conforman pospongan el consumo de alimentos y eviten con ello la adversidad y los riesgos de hambre a los que están expuestos, por depender directamente de los recursos disponibles en el medio. Las características antes descritas, presentes en la sociedad de los cucapá, hicieron posible que el encuentro entre éstos y grupos reducidos de estadunidenses fuera pacífico, y que después de establecer una especie de relación simbiótica, los aborígenes modificaran parcialmente sus hábitos alimenticios y sus actividades de subsistencia. (Sobre las formas de subsistencia de las sociedades de tecnología simple véase el ensayo de Daryll Forde titulado Economla primitiva en hombre, cultura y sociedad. Harry L. Shapiro, 1975 : 436-437 y 449 ). 
que pretendía imigar. La posibilidad de construir un tramo de canal a través de las dunas estaba entonces descartada por los elevados costos que la obra implicaba. Para realizar el ambicioso plan de irrigación de terrenos y colonización, Rockwood y sus socios organizaron varias empresas, las más importantes fueron la Imperial Land Company que se encargaba de la colonización propiamente dicha, la California Development Company, responsable de los proyectos de riego y suministro de agua y la Sociedad de Riego de Terrenos del Río Colorado, compañ́a subsidiaria que aseguraria el permiso del gobiemo de México para acarrear el líquido al territorio estadunidense (Herrera, 1976;17). Después de conseguir apoyo financiero, el cual implicó una extenuante bósqueda de inversionistas en Boston, Nueva York, Londres y Escocia, Rockwood y consocios lograron reunir los recursos necesarios para iniciar la empresa (Rockwood, 1930:9-12). Con una importante campaña publicitaria, la Imperial Land Company dio a conocer en varios estados de la unión americana el potencial agrícola de la región que deseaba desarrollar. Al finalizar el verano de 1900 la campaña atrajo a un buen número de colonos y su establecimiento oblig6 a la compañía a delimitar los sitios de los poblados que conformaron parte del actual Valle Imperial: Caléxico, Heber, Brawley e Imperial, En mayo de 1901 las obras de irrigación estuvieron listas y comenz6 la derivación, la corriente del río Colorado cruzó la frontera en junio (Henderson, 1968:17). Con esa agua se irrigaron algunas parcelas en las que los colonos cultivaron los productos agrícolas como sorgo, maíz milo, trigo y avena; también se hicieron siembras experimentales de melón y algodón (Howe y Hall, 1910:75).

Bl auge del Valle Imperial ocurrió entre la primavera y el otoño de 1903. En abril el total de acres cultivados era aproximadamente de 25000 (Farr, 1918;15). Es probable que durante la primavera de ese año hubieran más acres listos, los que no fueron sembrados pues el sistema de riego, aunque ya tenía 700 millas de canales, era insuficiente para irrigar todos los terrenos. En diciembre los acres cultivados no fueron menos de 100000 , la zona se poblaba rápidamente y el número de habitantes era ya de 7000 (Howe y Hall, 1910:95). El progreso económico de los agricultores del Valle Imperial exigí el establecimiento de eficientes vías de comunicación y transporte. Era necesario asegurar a los colonos el traslado de su producción a los centros de consumo, por esta razón, las compañías involucradas en el desarrollo del área, junto con una organización llamada Imperial \& Gulf Railroad Company promovieron la entrada del ferrocarril. La comunicación del Valle Imperial con los centros urbanos de los Estados Unidos fue posible en poco tiempo porque la línea intercontinental del Ferrocarril Pacifico del Sur (Southern Pacific Railway) pasaba cerca, en 
el noroeste. Desde 1902 comenzaron los trabajos de construcción de la vfa. Ese mismo año se termin 6 el primer tramo que puso en contacto a un lugar conocido como Old Beach (hoy Niland) con el poblado del Imperial (Kirchener, 1988:64), Dos años después el ferrocarril llegó a Caléxico, el poblado limítrofe de la unión americana, pero el tendido de durmientes no se detuvo alli, sino que, con autorización del gobiemo de México, cruzó la frontera y pasó por el naciente poblado de Mexicali, para luego continuar hacia un lugar llamado Bataques. Según el plan, el trayecto seguiria en territorio mexicano hasta el rancho fronterizo Los Algodones, para unirse finalmente a la vía intercontinental que vinculaba el oriente y el occidente de los Estados Unidos (Kirchener, 1988:64).

El paso del ferrocarril por casi todos los poblados del Valle Imperial aumentó la confianza en el desarrollo agricola de la zona y favoreció aún más la colonización. Aparentemente todo marchaba bien, pero en el verano de 1905 el optimismo de los colonos y el de la Califomia Development Company se oscurecio. Un problema de insuficiencia de agua, originado por el azolve del canal Álamo, conducto principal de la red de canales que distribuían el agua en el Valle Imperial, obligó a la California Development Company a crear tres tomas provisionales, a fin de acrecentar la corriente abastecedora. Las tomas fueron hechas en los años 1902,1903 y 1904 . La última fue la más grande de todas, midio 3300 pies de largo (poco más de un kilómetro) y 60 pies de ancho (18 metros) y a pesar de su tamaño no se le construyó compuerta, pues se planeo cerrarla antes de la temporada de crecientes del rio (Henderson, 1968:17). Los ejecutivos de la Califomia Development Company no ignoraron el hecho de que los tres canales provisionales eran puertas abiertas al poderoso caudal del Colorado, pero supusieron que no habria peligro, pues en los inviemos de 27 años anteriores solo se habfan registrado tres crecientes (Rockwood, 1930:35). Desgraciadamente, a finales de 1904 y en los primeros meses del año siguiente, el rio Gila tuvo cinco crecientes que aumentaron considerablemente el volumen del Colorado. Al terminar la quinta crecida, en el verano de 1905 , la última toma se ensancho y se hizo tan profunda que prácticamente toda la corriente del río fluyó por el canal Álamo y fue a llenar la cuenca del Mar Salton, deposito natural localizado al norte del Valle Imperial (Henderson, 1968:17; Kirchener, 1988:259). Los meses restantes del año 1905 y en el curso de 1906, la compañla realizó varias operaciones para cerrar las tomas provisionales y evitar la inminente inundación de Mexicali y de los poblados del Valle Imperial, pero, a pesar de los trabajos realizados, que costaron varios miles de dólares, el rfo siguió fluyendo sin control hacia el mar Salton. Un elemento importante en la solución del problema fue la infraestructura del ferrocarril recientemente 
creada. A través de las vías existentes y de otras que se tendieron a proposito, el tren transporto a la zona de desastre 1159 vagones de arcilla, 1094 de grava y 2157 de rocas que durante trece días fueron arrojados al rio (Estrella, 1981:78). Finalmente, el peso, la consistencia y el volumen de estos materiales obstruyeron las puertas falsas y la corriente regres 6 a uno de sus antiguos cauces en febrero de 1907 (Henderson, 1968:17).

La desviación accidental del río prolongada durante un año y medio resultó verdaderamente costosa. El dinero gastado por la compañfa ferrocarrilera en la clausura de la fuga fue mayor al millón y medio de dólares (Estrella, 1981:78), pero el costo de los daños en los poblados, así como en los canales y en las instalaciones también fue alto. La crisis provocada por la desviación del río y por la inundación tuvo además repercusion entre los cucapá. Sólo que a los indígenas no les afectó el exceso de agua sino su escasez, pues mientras en las áreas cercanas al canal Átamo la hubo en abundancia, en los terrenos sureños se padeció una grave sequía. Después de la fuga de la corriente hacia el mar Salton, el cauce del río Colorado estuvo seco, de modo tal que languideció la vida que bullía dentro de él, en sus riberas y en el estuario. Debido a esto, por un lapso de aproximadamente dos años, los cucapá no tuvieron manera de hacer ningún cultivo (Castetter y Bell, 1951:83), tampoco pudieron recolectar las plantas silvestres como el quelite, el arroz silvestre y el tule que crecían en su territorio gracias a la humedad y los desbordamientos del río. Los indígenas no desconocían la falta de agua, pues había años en los que el volumen de la corriente era exiguo y no ocurrian las inundaciones. Esta carencia significaba periodos difíciles para ellos, pues no tenían la irrigación necesaria para sembrar y la ausencia de agua repercutía también en la existencia de las plantas que recolectaban en los márgenes del río y en el estuario. Los cucapá acostumbraban almacenar una parte de los productos silvestres y agrícolas que obtenían al finalizar el verano. Con estas provisiones enfrentaban la escasez de alimentos en los meses de abril y mayo del siguiente año. En este periodo sobrevivían casi exclusivamente con lo almacenado (Kelly, 1977:25-26), por eso, cuando fallaban los escurrimientos del río no había gran cosa para guardar y se originaba una incertidumbre a la que debieron estar más o menos acostumbrados. En comparación, la ausencia completa del agua en el cauce, por más de un año debió crear entre ellos una incertidumbre mayor.

Desde mediados del siglo XIX hubo familias que fueron empleadas por la compañía naviera en el corte de leña o por la compañía agrícola en el corte de cáñamo silvestre en la colonia Lerdo. A cambio del desempeño de estas actividades los indígenas recibían dinero con el que compraban artículos en el mercado, Estos bienes, que alguna vez fueron un lujo, gradualmente dejaron 
de ser artículos de uso ocasional para convertirse en cosas de utilidad diaria. Camisas, levitas, pantalones, vestidos y alimentos como ta harina, el azúcar o el café, llamativos al principio por ser ajenos a su cultura, fueron incorporándose gradualmente a su forma de vida como bienes necesarios. Así fue que, con el propósito de obtenerlos, mantuvieron relaciones con estadunidenses y eventualmente desarrollaron algún trabajo para ellos. Para los cucapá los alimentos procesados no eran completamente necesarios, ya que a lo largo de las estaciones podían alimentarse con pescado, aves, mamíferos pequeños y plantas domésticas o silvestres, pero en el periodo de sequía, de 1905 a 1907, los alimentos del hombre "blanco" ganaron importancia y la economía de mercado debio convertirse en algo vital para ellos.

A causa de la sequía muchos cucapá se vieron obligados a trasladarse al norte, donde encontraron empleo en la reconstruccion del sistema de riego del Valle Imperial y en su posterior expansion. Sólo unos pocos permanecieron en el bajo delta y sobrellevaron la escasez de agua y alimentos (Castetter y Bell, 1951:83). Parece claro que la sequía propició que muchos cucapá, quizá aun aquellos que habian estado ajenos a las actividades de los "blancos", salieran en busca de un trabajo asalariado para subsistir. Cuando el río volvió a tener vida en sus contornos, los indios estuvieron en condiciones de regresar a su antigua forma de subsistencia, sin embargo, muchas familias comenzaron a concederle igual importancia al trabajo remunerado. Los cucapá aprovecharon toda actividad y ocasión para obtener los bienes a los que se hablan acostumbrado en el curso del contacto con mexicanos y estadunidenses. ${ }^{8}$ En esos años la harina, el azúcar y el cafe ya eran tan importantes como el mafz, el frijol, el quelite y las demás plantas silvestres que originalmente integraron su dieta (Rodriguez, 1976:23),

En el año 1907 la compañía ferrocarrilera reanudo los trabajos de construcción que habfan sido interrumpidos a causa de la inundación. De entonces a 1909 construy 6 varias estaciones y la vía que unió al poblado de Mexicali con el rancho Los Algodones. Para ese tiempo, una buena parte de los individuos integrantes de la tribu hicieron repetidos viajes hacia el norte y se establecieron temporalmente en el poblado de Mexicali, en varios lugares proximos a la línea divisoria, a lo largo de la ruta del ferrocarril y en los valles Imperial y de Yuma (Kelly, 1977:13). A finales de 1909 había entre 70 y 80 familias cucapá instaladas en las inmediaciones de Mexicali y de Yuma (Williams, 1975:133). Desde

VEase como ejemplo el relato de Arthur W. North en Travelers among the Cucapd (Williams, 1975:127-128). 
entonces, las travesfas realizadas por ellos en busca del sustento tuvieron como punto final no sólo el estuario donde recogían arroz silvestre, o la sierra alta (sierra de Juárez) donde recolectaban piñon y bellota (Kelly, 1977:34, 39 y 40), sino los sitios en los que podían ser empleados por las compañías dedicadas a la construcción de canales o en la nivelación de terrenos para el cultivo. Una nota breve, escrita en ese tiempo por un viajero anglosajón, esboza esta nueva condición de los cucapá:

...viajamos hacia el norte y el noroeste, explorando el territorio de los Cocupas.(sic) Encontramos un gran número de chozas de indios, de las cuales la mitad estaban abandonadas, los ocupantes habían ido al suroeste en busca de piñones o hacia el norte a trabajar para los blancos a lo largo de la línea divisoria. (Williams, 1975:120).

Otra un poco más extensa, redactada por un agente del gobierno local e incluída en un reporte estadístico ilustra mejor el punto.

Los indígenas de esta tribu viven en las márgenes del tío Colorado...su población constante en aquellas regiones asciende a la cantidad de 192 hombres y 157 mujeres, la existencia de indígenas pertenecientes a dicha tribu es mucho mayor, pero existen diseminados en los distintos trabajos de irrigación, limpia de canales y demás que existen en el Valle a uno y otro lado de la línea internacional, pudiéndose asegurarse que el número de ellos asciende a la cantidad de setecientos, pues aun cuando trabajan en diversas partes, siempre ocurren periódicamente al lugar de su residencia (Rodríguez, 1976:23).

\section{EL DESARROLLO AGRÍCOLA EN EL VALLE DE MEXICALI 1912-1925}

La creación de la importante infraestructura en el Valle Imperial que se extendió más alla de la línea fronteriza en la primera década del siglo XX facilito el desarrollo agrícola de la región sureña que llevaría el nombre de valle de Mexicali. Mientras los colonos del Valle Imperial recogían sus primeras cosechas, el general Harrison Gray Otis, Harry Chandler y un grupo de inversionistas estadunidenses aprovecharon las facilidades que el gobiemo de Porfirio Díaz había otorgado a las compañías colonizadoras en el norte de México, para hacerse propietarios de una gran extensión de terrenos en la región del bajo delta. En el año 1902 constituyeron la California Mexico Land \& Cattle Company, así como una filial llamada Colorado River Land Company (Grijalva, 1983:352-353). Entre 1904 y 1907 la Colorado River Land Company efectuó seis transacciones que la hicieron propietaria de 325492.525 hectáreas de terrenos de la región del bajo delta (Grijalva, 1980:29-30). Después de realizar dichas compras 
Otis, Chandler y demás accionistas invirtieron 12000000 de dólares en la nivelación de terrenos, construcción de canales, diques y caminos vecinales y en diversas mejoras para la utilización de las tierras (Grijalva, 1983:356), con ello el consorcio no estaba creando las condiciones para colonizar, ni para explotar la tierra directamente, pues había encontrado una manera más segura de obtener utilidades. A partir de 1912 la Colorado River Land Company definio los mecanismos que habrían de convertirla en una empresa multimillonaria, a través de lucrativos contratos de arrendamiento (Grijalva, 1983:357). Poco después, diferentes grupos asiáticos comenzaron a establecerse en el valle de Mexicali y a cultivar las tierras que rentaron a la compañía. Los arrendatarios y subarrendatarios fueron en su mayoría chinos, pero también hubo japoneses, hindúes y estadunidenses. Los contratos de arrendamiento no eran del todo ventajosos para los arrendatarios, no obstante, año tras año fue incrementándose el número de hectáreas irrigadas y cultivadas. En 1913 la superficie bajo riego era de 5 570, las cuales se convirtieron en 15925 al año siguiente y llegaron a las 27816 en 1916 (Rojas, 1989). Ese mismo año los agricultores obtuvieron una cosecha de algodón valuada en un millón de dolares ${ }^{9}$ (Grijalva, 1983:357). A mediados de la década de los años veinte el progreso de la Colorado River Land Company y el desarrollo económico del valle de Mexicali eran obvios: una amplia extensión de terrenos se hallaba cultivada, se habían abierto caminos e instalado vías férreas y las aguas del río Colorado estaban siendo aprovechadas, pero también era evidente que dicho desarrollo era ajeno a México y que estaba vinculado al suroeste de los Estados Unidos, que la tierra estaba acaparada por compañías extranjeras y que los requerimientos del gobierno mexicano en tomo a la colonización no habían sido atendidos (Grijalva, 1988:29).

\section{LA DISPUTA POR EL AGUA DEL RÍO COLORADO 1920-1935}

Después de las grandes crecientes y la inundación ocurridas en los años 1905 y 1906, los colonos del Valle Imperial vivieron con el temor de que la falta de agua o una sorpresiva inundación afectaran sus cosechas y propiedades. Contra las inundaciones habían construido varios bordos de prevención en territorio mexicano, pero para evitar la escasez de agua no tenían todavía una solución. En los años veinte no sólo los colonos del

\footnotetext{
9 Desde principios de siglo el algodón fue un producto bien cotizado en el mercado internacional, esta circunstancia, aunada al hecho de que las características climatológicas del valle de Mexicali eran óptimas para el desarrollo de esta planta, llevaron a la Colorado River Land Company a privilegiar su cultivo sobre otros productos agrícolas.
} 
Valle Imperial estaban preocupados por el control y el suministro de agua, la década había comenzado con una disputa por el río entre los usuarios de los estados del país vecino por donde éste cruzaba. Debido a la creciente necesidad de agua para uso urbano y agrícola en Wyoming, Utah, Colorado, Nuevo México, Nevada, Arizona y California, funcionarios representantes de cada uno de estos estados se reunieron para discutir un arreglo sobre la distribucion del líquido. Previamente se habian realizado varios estudios que plantearon la urgencia de construir grandes presas de almacenamiento y la necesidad de independizarse de México en la conducción del volumen requerido en el Valle Imperial. Como resultado de esas reuniones, los estados en disputa acordaron, en un convenio conocido como Pacto de Santa Fe, firmado en Nuevo México en noviembre de 1922 , dividir los volúmenes del río en partes iguales y se estipuló que las aguas que debían entregar a México por compromiso internacional, serian tomadas de los excedentes de la cuota de cada uno. En caso de que dichos excedentes no fueran suficientes, el faltante serfa cubierto por los estados en partes iguales (Sánchez, 1990:172-173).

En la region del bajo delta los derechos para conducir por territorio mexicano el agua del río Colorado hacia el Valle Imperial, estuvieron inicialmente en poder de la Sociedad de Irrigación y Terrenos de la Baja California. Esta organizacion creada por Rockwood, manejaba conjuntamente con la California Development Company las cuestiones de irrigación, pero debido a las deudas contraidas a causa de la inundación de 1905 , las empresas de Rockwood se vieron obligadas a entregar los derechos a la compañía ferrocarrilera que soluciono el problema de la fuga del río (Herrera, 1976:97). En agosto de 1910 la empresa ferroviaria formó una nueva organización para el manejo del agua en México, se llamo Compañía de Terrenos y Aguas de la Baja California. Aproximadamente un año después de su constitución, los colonos del Valle Imperial promovieron la creación del Distrito de Riego Imperial para administrar la distribución del agua en la red de canales. Posteriormente, en 1916, todas las propiedades e instalaciones relacionadas con la irrigacion fueron entregadas a ese distrito de riego, incluida la Compañía de Terrenos y Aguas de la Baja California (Sánchez, 1990;158-159). La creación del Distrito de Riego Imperial apaciguó parcialmente los temores de los colonos, sin embargo, había todavfa aspectos asociados con la irrigación que les originaba intranquilidad. A principios de siglo el gobierno mexicano autorizo a Rockwood y sus socios derivar y conducir el agua del río Colorado en territorio nacional con la condición de que se destinara a México el cincuenta por ciento del total de agua derivada y ese acuerdo seguía vigente (De Vivanco, 1925:353). Por otra parte, la Secretaría de 
Agricultura y Fomento estableció en el año 1906 una dependencia llamada Comision Revisora de Aguas, que superviso las actividades de la Compañía de Terrenos y Aguas de la Baja California, con el proposito de evitar privilegios (Sánchez, 1990:158). En general, el hecho de que el liquido para riego cruzara por territorio mexicano era visto por los agricultores del Valle Imperial como un gran inconveniente, por eso estaban empeñados en construir un canal autónomo para su sistema de irrigacion.

Al inicio de la década de los años treinta se registró un volumen de agua exageradamente reducido en el río Colorado debido a la falta de nieve en las montañas donde tiene su origen. En el año 1933 el caudal decreció tanto en la zona del bajo delta que fue necesario repartir el agua disponible entre las regiones fronterizas de Estados Unidos y México, para evitar conflictos internacionales. La cantidad destinada a nuestro país fue dividida después entre las compañías agrícolas y los colonos del valle de Mexicali (Basich, 1982), Esta escasez de agua en el río se prolong6 hasta 1934, Desde marzo la Comisión Revisora de Aguas informó a los usuarios que debfan anticipar riegos, entonces el volumen derivado descendí a cinco milímetros cúbicos por segundo en la bocatoma principal. Para evitar una sequía absoluta, en las ciudades del Valle Imperial se improvisaron grandes depósitos en los que se almacenó agua para uso doméstico y se prohibió utilizarla en jardines. Pero las medidas de prevención no pudieron evitar la pérdida de los cultivos perennes (Basich, 1982). Alli, como en el valle de Mexicali, la producción agrícola disminuyó notablemente. Esta nueva sequía, debida a circunstancias naturales, también tuvo repercusioaes en la comunidad cucapá.

En menos de treinta años la existencia de los cucapá, relacionada directamente con la vida animal y vegetal que bullía en torno al rio Colorado, se vio alterada por dos graves sequías. La primera fue provocada por la desviación de la corriente hacia el mar Salton; la segunda fue de orden natural, pero en la cuenca baja se agravó con la conducción de la poca agua hacia los campos agrícolas. La sequía en todo el valle, o mejor dicho en los valles, significo otra dura lección para los cucapá. Para entonces quienes babian padecido la escasez de agua y alimentos en los años 1905 y 1906, deben haber tenido la certeza de que el Colorado ya no les pertenecía. Los que vivían todavía con los alimentos cultivados, con los que pescaban, cazaban o recolectaban, debieron convencerse de que ya no sería posible subsistir con los recursos que les había ofrecido el río. Adela Sandoval Portillo, integrante de una familia constituida por cucapás indígenas y cucapás mestizos recuerda asf los estragos provocados por la ausencia del cuerpo del río en el año 1933. 


\begin{abstract}
Cuando murió mi abuelo nos venimos a este lugar (el actual ejído Cucapá Mestizo) a ver si agarrábamos la pizca y nos enseñábamos a trabajar. Nos vinimos de El Mayor porque todo estaba muy seco, no había pescado ni nada. Actualmente casi no hay agua en el río ¿verdad? pero no se compara, entonces estaba partida la tierra, partida por la sequedad y las grietas eran tan grandes que les cabía un zapato. Lo único verde eran los mesquites, los sauces y los pinillos, todo to demás se veía como cuando se acaban las siembras, como cuando viene una helada y deja todo amarillo, así estaba. Entonces la situación se puso muy dura, hasta para los animales, bubo una mortandad de aves, mortandad grande. En el lecho del río había pescados muertos y en todas partes apestaba el animalero. También la gente andaba desesperada, en esa época se trabajaba el día por un kilo de frijol. Mis tíos escarbaban por el paredón de los brazos del río, hacian pozos profundos para sacar agua, así es como teníamos para beber. Yo oía a los grandes decir que había una sequía porque no hubo nevadas en el norte, pero yo creo que deben baber hecho un represo allá en Estados Unidos y de repente se acabó el agua. Eso fue en el treinta y dos, o en el treinta y tres, no estoy segura, lo que sé es que de las sequías que recuerdo, no hubo ninguna como esa (Sandoval Portillo, Historia Oral, 1990-1993).
\end{abstract}

En 1935 se terminó en Estados Unidos la construcción de la gigantesca presa Boulder, llamada después Hoover. Esta obra, considerada como la más grande del mundo, fue creada para controlar el flujo del Colorado. En 1936 la presa inició sus actividades y su funcionamiento provocó protestas del gobierno de México, en vista de que el control del agua modificaría las condiciones de un río intemacional. Los reclamos desde luego resultaron inútiles (Sánchez, 1990:175). El almacenamiento de grandes volúmenes de agua en la presa Hoover fue nocivo para las compañías agrícolas y para los colonos establecidos en el valle de Mexicali, pero sobre todo para los cucapá, pues en la disputa del agua, los indígenas no tuvieron posibilidad de ser considerados.

En el mes de enero de 1937 un grupo de campesinos del valle de Mexicali, organizados en la llamada Confederación de Comunidades Agrarias del Territorio Norte de Baja Califomia, invadio las tierras de la Colorado River Land Company, como medida de presión para que les fuesen resueltas sus peticiones de tierra. El entonces presidente Lázaro Cárdenas decidió expropiar a la compañía 118819 hectáreas (Grijalva, 1978:127) para fraccionarlas, repartirlas y comenzar la postergada colonización de la región. A finales de ese año, por resolución presidencial, las autoridades agrarias crearon 44 núcleos ejidales y se otorgaron 97121 hectáreas de tierras abiertas al cultivo que fueron distribuidas entre 4389 
familias (Grijalva, 1978:128). Entre los ejidos creados estaban los llamados Cucapá Indígena y Cucapá Mestizo, destinado uno a familias aborígenes y el otro a familias mixtas. Pero no todos los cucapá se entusiasmaron con el sistema ejidal, ni todos pudieron conservar sus derechos sobre las parcelas. La deficiente dirección de las autoridades agrarias, aunadas a la incapacidad organizativa y a la falta de interés de los indios (Kelly, 1977:13) tuvieron como resultado el abandono de las tierras ejidales, sobre todo en el ejido Cucapá Indígena, y propiciaron la entrada de familias mexicanas. En opinión de Adela Sandoval Portillo, las cosas ocurrieron así:

Después de que nos repartieron las parcelas, muchos cucapás las abandonaron o las vendieron, quién sabe por qué. Será por lo que siempre se ba dicho, de que el indio de aquella época era débil de cerebro, y como nunca en su vida babía tenido nada, pues las tierras las miraba como nada, o sea que como luego dicen, no tenía amor por el suelo. O será porque la gente que vino de Juchipila, de Zacatecas, o sepa Dios de dónde... los amiedaron, los emborracharon, les dieron dinero, los golpearon, les hicieron miles de cosas, hasta que toda la indiada que tenía los títulos de esas tierras a su nombre mejor se fue para los Estados Unidos. Otros pues las vendieron... (Garduño, 1991:46).

En los años posteriores a 1937 la repartición de tierras continuó, consecuentemente la superficie que debía ser irrigada se amplió y creció la demanda de agua. Debido a que entonces ya existían numerosos sistemas de riego, administrados por la Compañía de Terrenos y Aguas de la Baja Califomia, como por particulares, propietarios de canales y plantas de bombeo, el gobiemo mexicano creo en agosto de 1938 el Distrito de Riego del Río Colorado. Esta dependencia tenía la tarea de organizar y controlar la distribución del agua, así como conservar los sistemas de irrigación existentes (Soleno, 1972:56), Y mientras en el valle de Mexicali aumentaba el número de ejidatarios, en el otro lado de la línea divisoria los agricultores del Valle Imperial se disponían a festejar la llegada de las primeras aguas derivadas y conducidas completamente en territorio estadunidense. En efecto, el empeño por conseguir la construcción de un sistema de irrigación propio fructific 6 en 1928, al ser aprobadas las presas Hoover e Imperial y un canal autónomo (Sánchez, 1990:174), pero no fue hasta el año 1942 cuando el largamente deseado canal comenzó a funcionar. El nuevo conducto recibio el nombre de canal Todo Americano (All American) y con él los agricultores estadunidenses estuvieron en condiciones de prescindir del canal Álamo y pudieron conducir cabalmente el agua del 
Colorado dentro de su país. Esta circunstancia nulifico el compromiso de entregar a México cualquier cantidad de agua. Posteriormente, en vista de que no había un convenio formal entre México y Estados Unidos sobre la repartición del agua, los estadunidenses la acapararon y sólo después de satisfacer sus necesidades de riego, enviaron los volúmenes sobrantes, De este modo se invirtieron los papeles en el manejo del agua, y el suministro para el valle de Mexicali se hizo azaroso y perjudicial para los ejidatarios y demás agricuitores (Sánchez, 1990;175), El problema del agua planteó al gobierno de México la urgencia de llegar a un acuerdo con los Estados Unidos para garantizar el ingreso de volúmenes fijos al valle de Mexicali. Luego de varias reuniones entre representantes de ambos países, fue firmado el Tratado sobre Aguas Internacionales, en febrero de 1944. Por medio de éste se establecio que nuestro pafs recibiria un volumen calendarizado de $1854234000 \mathrm{~m}^{3}$. Se acordo también que de haber excedentes en los Estados Unidos podran entregarse a México $21096931000 \mathrm{~m}^{3}$. En caso contrario, cuando no fuera posible la dotación normal, la cuota se reduciría en la misma proporción que las cuotas de los estados de Estados Unidos usuarios del río (Sánchez, 1990:175-177).

Para el año 1944 las autoridades agrarias de México ya habian repartido un total de 189687 hectáreas de tierras con fines agrícolas en el valle de Mexicali y en San Luis Río Colorado, Sonora, todas dependientes del río Colorado para su irrigación. Después de la ratificación del tratado đe aguas, se supo con certeza que el volumen asignado a México sería insuficiente para regar cabalmente la superficie total de los ejidos, colonias y pequeñas propiedades, no obstante, se fundaron nuevos ejidos y colonias y con ello se amplió la superficie cultivada a 275000 hectáreas (López Zamora, 1977:37). El problema de insuficiencia de agua no se presento mientras hubo grandes volúmenes en el río Colorado, de hecho los colonos y los ejidatarios del valle de Mexicali consiguieron buenas cosechas y lograron cierto progreso económico, pero años más tarde comenzaron las dificultades, cuando los estadunidenses redujeron los volúmenes de agua a los límites establecidos en el tratado de 1944. Entonces la falta de agua provocó grandes pérdidas en la agricultura y surgieron conflictos entre los usuarios y autoridades encargadas de la distribucion (López Zamora, 1977:25 - 39). No está de más decir que en la repartición del mermado río las necesidades de las familias cucapá estuvieron fuera de la discusion.

La distribución del agua del río Colorado en las redes de canales en el valle de Mexicali y en el Valle Imperial, y el almacenamiento de grandes volúmenes en las presas construidas en Estados Unidos, provocaron cambios y alteraciones en el paisaje del bajo delta. En la década de los años cuarenta el agua conducida por el hombre llego a lugares que antes no 
habían sido alcanzados por los desbordamientos naturales del río. El desierto fue transformado gradualmente, pero, del mismo modo, la vida abundante que existía en los contornos del río desapareció. El nuevo uso del agua provoco la disminucion de la corriente que flufa en el cauce principal del Colorado y en el de sus ramales y desde luego decrecio la cantidad descargada en el golfo de California, con ello cambio la configuración ambiental de la zona deltaica.

La disminución del agua modificó la riqueza en número y tipo de especies de agua dulce y salada que existían en la región. La caza, la recolección de frutos silvestres mermaron al afectarse las relaciones tróficas de las especies, al disminuir por una parte el agua y junto con ella la flora y la fauna asociada. Esto contribuyó a la migración o extinción de las especies terrestres y marítimas (Rojas, 1989).

Los cucapá, que tradicionalmente obtenfan de este medio la mayor parte de sus recursos alimenticios, se vieron obligados a adaptarse definitivamente a la nueva situación. Para ellos la pérdida de su territorio fue ostensible, sin duda, cuando se crearon los ejidos en el valle de Mexicali. Es cierto que antes la zona habla sido poblada por chinos, estadunidenses, japoneses e hindúes, jomaleros y arrendatarios de la Colorado River Land Company, pero el avance de la superficie irrigada y cultivada fue gradual y permitio a los indigenas subsistir con la caza, la pesca, la recolección y la agricultura. Con el establecimiento de miles de campesinos mexicanos migrantes, convertidos gracias a la aplicacion de la reforma agraria en colonos y ejidatarios, se cré una situación distinta y significó la pérdida completa de su antiguo territorio.

Hoy día, los descendientes de los antiguos cucapá se encuentran establecidos en Arizona (Estados Unidos), en Sonora y en Baja California (México). En Arizona viven en Yuma y en Somerton, en reservaciones indigenas; en Sonora hay unas pocas familias asentadas en el ejido Pozos de Arvizu y en San Luis Río Colorado; en Baja Califomia el grueso de la población se concentra en el poblado El Mayor, aledaño al rio Hardy, uno de los ramales del Colorado, pero hay también familias en algunos ejidos del valle y otras en la ciudad de Mexicali. La poblacion de Baja California y Sonora que vive en los ejidos se dedica a la agricultura en sus parcelas ejidales, los demás son pescadores o trabajadores asalariados. Unos y otros elaboran, para vender, adomos de chaquira tejida, semejantes a los utilizados por los cucapá de principios de siglo como ornamento. Actualmente quedan escasos vestigios de la cultura aborigen cucapá, la mayorfa de los primeros mestizos ya desaparecieron y con ellos se perdieron en el tiempo los conocimientos y las técnicas de sus antepasados, mismas que durante 
siglos, les permitieron subsistir en un medio riguroso y vivir en comunion con el desierto y con el río Colorado.

A pesar de la pérdida de una gran parte de sus recursos culturales, los descendientes de los cucapá en Baja California han conservado su identidad étnica que los mantiene en cierto modo apartados del resto de la población. Los cucapá, al igual que los otros grupos indigenas del norte de Baja Califomia, han mostrado interés en mantenerse unidos con objeto de conseguir reivindicaciones sociales y económicas. Esta necesidad de agruparse ha contribuido a la cohesion de las familias mestizas sobrevivientes, que defienden su identidad indigena, a pesar de que desde hace varias décadas, en su condición de trabajadores asalariados y ejidatarios comparten las características sociales y culturales con la población del valle de Mexicali.

\section{A MANERA DE CONCLUSIÓN}

Por medio de este trabajo hemos establecido algunos aspectos generales del desarrollo histórico de la tribu cucapá, a partir de eventos y procesos de orden social y economico externos a la comunidad indigena. Dichos aspectos se refieren básicamente al modo de subsistencia de la tribu y a los cambios sucesivos que la afectaron desde la segunda mitad del siglo XIX, a rafz del contacto con agentes de la cultura occidental. El texto se centra en la relación de dependencia de los cucapá respecto al río Colorado y en el derrotero que siguieron ambos, después de que la población no indígena se establecio en la región y se adjudico el manejo del agua del rfo. Asf bemos descrito cómo en las primeras tres décadas del presente siglo, la apropiación hidrálica por parte de los "blancos" provocó dos severas crisis que repercutieron negativamente en la organización social y económica de los cucapá. Al centrar nuestro interés en los cambios relacionados con su modo de subsistencia, hemos dejado de lado otras relaciones enmarcadas en el contacto, que son igualmente importantes. Una de ellas es la exogamia, cuyo resultado, el mestizaje, influyo definitivamente en la desintegración tribal. También hemos dejado al margen la organización política indígena y su capacidad para oponerse a las apropiaciones (tierra-agua) y a los cambios impuestos por los "blancos". Por esta razón es necesario realizar otras investigaciones, ya que mediante el desarrollo de éstas tendremos información adicional para acceder de manera más completa a la historia de este grupo indígena, sólo entonces podremos establecer el orden y la trascendencia de cada uno de los factores que determinaron su condición actual. 


\section{BIBLIOGRAFIA}

APODACA Chavira, Ima. 1984. "Los Algodones. Poblado precursor". Calafia , vol.V, núm. 3. Universidad Autónoma de Baja California. BENDÍMEZ Paterson, María Jalita. "Historia Oral: Benito Peralta de Santa Catarina, comunidad pai pai." Cuadernos de Ciencias Sociales. Instituto de Investigaciones Sociales, UABC, serie 4, núm. 4.

BLANCO, Jacobo. 1978. Documento núm.35. Informe sobre la exploración en el río Colorado. Brand Book number five. San Diego Corral of Westerners, San Diego.

CASTETTER, Edward y Bell Willis. 1951. Yuman Indian Agriculture. Primitive Subsistence on the Lower Colorado and Gila Rivers. University of New Mexico Press.

CROWE, Rosalie y Brinckerhoff Sidney B. (editores), 1976. Early Yuma. A Graphic History of the American Nile. Northland Press.

DARYLL, Forde. 1975. "Economía primitiva", en Hombre, cultura y sociedad. Harry L. Shapiro (compilador). FCE.

DE VIVANCO, Aurelio. 1925. Baja California al día. Distrito Norte y sur de la península, editado por De Vivanco.

ESTRELLA, Gabriel. 1981. El proceso de urbanización del valle de Mexicali. Tesis de licenciatura en sociologia, Escuela de Ciencias Sociales y Políticas, UABC, Mexicali.

FARR, Finis C. 1918. The History of the Imperial County California. Elms and Franks, Berkeley.

FORBES, Jack. 1965. Warriors of the Colorado. University of Oklahoma Press, Norman.

FORDE, Daryll. 1931. Ethnography of the Yuma Indians. University of California Press, Berkeley.

- "Economfa primitiva". 1975, En: Hombre, cultura y sociedad. Harry L. Shapiro (compilador), FCE, México.

GARDUÑO, Everardo. 1991. Voces y ecos de un desiento fértil. Universidad Autónoma de Baja California, Mexicali .

GOLDBAUM, David. 1984. "Noticias respecto a las comunidades indigenas que pueblan el Distrito Norte de la Baja Califomia". Calafia, vol.V, núm. 3.

GÓMEZ Estrada, José Alfredo. 1989. "La aculturación de los indios cucapá en Baja Califomia". Tesis de licenciatura en sociología, Escuela de Ciencias Sociales y Políticas, UABC, Mexicali.

GONZÁLEZ Félix, Maricela. 1990. "El proceso de aculturación de la población de origen chino en la ciudad de Mexicali". Cuadernos de Ciencias Sociales, serie 4, núm.7, UABC. 
GRIJALVA, Edna Aidé. 1978. "El desarrollo del capitalismo en el valle de Mexicali". Tesis de maestría, Facultad Latinoamericana de Ciencias Sociales, México.

- 1980. "Una aproximación al estudio de una empresa agrícola. La Colorado River Land Co. S.A." Calafia, vol.Iv, núm.3.

- 1983. "La Colorado River Land Company". En: Panorama Historico de Baja California. Centro de Investigaciones Históricas UNAM-UABC, Mexicali.

- 1988. "Gambusinos del desierto. Los otros pioneros del valle de Mexicali". Calafia, vol.vi, núm.4.

- 1988. "Desventuras y desasosiegos de los colonos bajacalifornianos ante la legislación liberal, 1857-1875". Meyibó, vol.m, núm. 7-8, UABC.

HENDERSON, Tracy. 1968. Imperial Valley. Neyenesch, San Diego.

HENDRICKS O., William. 1976. "The Lost Cocopa Reservation". Pacific Coast Archaeological Society, vol.12, núm.1.

HERRERA Carrillo, Pablo. 1976. Colonización del valle de Mexicali. Universidad Autonoma de Baja California, Mexicali.

HICKS, Frederic. 1974. "The Influence of Agriculture on Aboriginal Socio- Political Organization in the Lower Colorado River Valley". The Journal of California Anthropology. Malki Museum, Banning.

HOWE, Edgar F. y Hall Wilbur Jay. 1910. The Story of the First Decade in Imperial Valley California. Edgar F. Howe \& Sons, Imperial.

HUBERMAN, Leo. 1977. Nosotros, el pueblo. Historia de Estados Unidos. Editorial Nuestro Tiempo. México.

HU-DE HART, Evelyn. 1986. "The Chinese of Baja California norte 1910-1934". Proceedings of the Pacific Coast on Latin American Studies, vol.12, 1985-1986, San Diego State University Press, San Diego,

WILLIAM, Kelly H. 1977. Cocopa Ethnography. University of Arizona Press, Tucson.

KIRCHENER, John A. 1988. Baja California Railways. Dawson's Book Shop, Los Ángeles.

KNIFFEN, Fred, 1933. The Primitive Cultural Landscape of the Colorado Delta. University of California Publications in Geography, vol.5, Núm,2, Berkeley,

KROEBER, Clifton B. 1980. "Lower Colorado River People: Hostilities and hunger, 1850-1857". Journal of California and Great Basin Anthropology, vol.2, núm.2. 
LEON Portilla, Miguel. 1989. Cartografía y crónicas de la antigua Califormia. Universidad Autónoma de México, Fundación de Investigaciones Sociales A.C., México.

- 1983. "La labor de los dominicos". En Panorama Histórico de Baja California. Centro de Investigaciones Históricas, UNAM-UABC, Mexicali.

LEAVITT Frances, Hale. 1943. Steam navigation in the Colorado River. Historical Society Quaterly, vol. XXII.

LÓPEZ Zamora, Emilio. 1977. La tierra, el agua. Los hombres de México. Fondo de Cultura Económica, México.

MARTÍNEZ L., Pablo. 1956. Historia de Baja California. Libros Mexicanos, México.

NEVINS, Allen y Steel Henry. 1956. Breve historia de los Estados Unidos. Biografia de un pueblo libre. Compañía General de Ediciones, México.

ROBLES Marina, León Cuauhtémoc y Téllez Miguel. 1991. "Mexicali: crisol del desierto". En Mexicali. Una historia. Instituto de Investigaciones Históricas, UABC, Mexicali.

ROCKWOOD, Charles Robinson. 1930. Born of a desert. Calexico Chronicle Publisher, Caléxico.

RODRfGUEZ A. 1976, "Apuntes estadísticos de la tribu cucapa”" (introducción y notas de Jesús Ángel Ochoa Zazueta. Calafia, vol.II, núm. 2 .

ROJAS, Rosa Imelda. 1989. Agua, desarrollo e impacto ambiental. Xerox I Congreso Internacional sobre Fronteras en Iberoamérica Ayer y Hoy.

ROJO, Manuel Clemente. 1987. Apuntes históricos de la Baja California. Fuentes documentales para la historia de Baja California, año 4 , núm.5, UABC,

SÁNCHEZ, Oscar. 1990. Crónica agrícola del valle de Mexicali. Universidad Autónoma de Baja California, Mexicali.

SOLENO, Benavente Luis. 1972. "Estudio general sobre el aprovechamiento de las aguas del río Colorado en el valle de Mexicali y San Luis Río Colorado, Son." Tesis licenciatura, Escuela Superior de Agricultura Hermanos Escobar, Ciudad Juárez, Chihuahua.

WALTER Meade, Adalberto. 1983. Origen de Mexicali. Universidad Autónoma de Baja California, Mexicali.

- 1986. Distrito Norte de Baja California. Universidad Autónoma de Baja Califomia, Mexicali.

- 1991. "Exploraciones en el río Colorado", En Calafia, vol,vI, núm.8. 
WILLIAMS, Anita Álvarez de.1975. (compilador) Travelers among the Cucapá. Dawson's Book Shop, Los Ángeles .

\section{Historia Oral}

Enrique Basich. Entrevista realizada por Irma Apodaca. Mexicali 1982. Archivo del Instituto de Investigaciones Históricas, UABC.

Adela Sandoval Portillo. Entrevistas realizadas por José Alfredo Gómez Estrada. Mexicali 1990-1993. 